\title{
TRANSPORTE Y PRECIO DEL TRIGO \\ EN EL SIGLO XIX: \\ CREACIÓN Y REORDENACIÓN \\ DE UN MERCADO NACIONAL
}

RAFAEL BARQUINN GIL

Universidad de Burgos

\begin{abstract}
RESUMEN
El propósito de este trabajo es estudiar el proceso de integración del mercado del trigo en España en el siglo XIX. Básicamente, la integración fue creciente hasta mediados de siglo, y decreciente con posterioridad. El incremento de la producción agricola y la reducción de los costes del transporte explican la mejora de la integración de los años 1830/50. El proceso de desintegración resulta más enigmático, pero no parece que la construcción del ferrocarril haya contribuido a construir el mercado nacional. Al contrario, pudo haber sido la causa de esa desintegración, si bien, en algunos casos, mejoró la conexión entre algunos mercados
\end{abstract}

\section{ABSTRACT}

The aim of this paper is to study the process of integration of the XIX century Spanish market of wheat. Basically, integration grew until the middle of the XIX century, and decreased from then. The growth of agricultural production and the reduction of transport costs explain the improvement of integration in the period 1830/50. The process of disintegration is more enigmatic, but the advent of railway does not seem to have contributed to building the national market. On the contrary, it could be the cause of that disintegration, in spite of the fact that it improved the connection of some markets.

\section{LA FUNCIÓN CRUZADA DE COEFICIENTES DE CORRELACIÓN}

La transición de una economia tradicional a otra moderna tiene en la integración de los mercados uno de sus indices más claros. Para Phyllis Deane su 
ausencia es uno de los rasgos de las economías preindustriales, junto a la pobreza, la dependencia de la agricultura, el estancamiento y la falta de especialización laboral 1.

En principio, dos mercados se encuentran integrados si es indiferente comprar o vender una mercancia en cualquiera de ellos. Ahora bien, por mercancía debemos entender no sólo el producto básico, sino también el valor añadido generado por las actividades terciarias. Así, el mercado internacional de cacao está integrado pese a que el precio en Ghana es muy inferior al de Londres. Lo que en la City se vende no sólo es cacao; también hay disponibilidad. Por tanto, un mercado integrado es aquel en el que el precio de una mercancía es la suma de su coste de fabricación en el lugar de producción y de su coste de distribución hasta el lugar de consumo (incluido el beneficio «normal» del distribuidor). $\mathrm{Ca}$ lificar a un mercado como integrado exigiria comparar el precio real de la mercancia con este valor teórico, lo cual es muy complicado.

Existe un procedimiento alternativo. Si los precios de dos mercados mantienen una relación estable, podemos deducir que existe un tráfico mercantil frecuente, y que los costes de distribución son estables. Por tanto, cualquier alteración en las circunstancias en las que operan productores, intermediarios y consumidores se reflejará en la relación que mantienen los precios de los mercados «productor» y «consumidor». Sin pretender ser exhaustivo, se pueden señalar las siguientes: a) la conexión del mercado consumidor con otros mercados; b) la incapacidad del mercado productor para satisfacer la demanda del mercado consumidor de forma regular; c) bruscas alteraciones en el comportamiento de los consumidores o productores ante la aparición de productos sustitutivos, variaciones en la renta, etc.; d) la existencia de prácticas monopolísticas.

Puesto que los productos agrícolas experimentan grandes fluctuaciones en su precio, la capacidad de un mercado «consumidor» para responder a éstas mediría su grado de integración con el mercado «productor» de referencia. Este es el punto de partida de Emilio Sereni. Para ciertos periodos, calculó el coeficiente de correlación entre series de precios de distintas plazas italianas en el siglo xIx. Un valor elevado de éste implicaba una notable integración. Así pues, la tendencia creciente o decreciente de dichos coeficientes marcaría la pauta en el proceso de formación del mercado nacional en la Italia pre y postunitaria. Un estadístico tan sencillo como el coeficiente de determinación se presentaba como el indicador más preciso de la modernización económica 2 El desarrollo lógico de este instrumento sería la construcción de matrices de

\footnotetext{
1 P. Deane (1988), pp. 23-25.

2 E. Sereni (1980), pp. 40-44.
} 
coeficientes 3, labor que en España fue llevada a cabo por Nicolás Sánchez-Albornoz para el periodo $1856-1890^{4}$.

Sin embargo, este procedimiento no es completamente satisfactorio. El coeficiente de determinación sólo indica la capacidad del modelo para explicar las fluctuaciones de los datos alrededor de su media. Por ello, su valor puede verse alterado si es calculado entre series que presentan una acusada tendencia o variabilidad ${ }^{5}$. Este problema se hace aún más grave si la serie presenta distintas tendencias y varianzas a lo largo del tiempo. Entonces se dice que no es estacionaria. Ello implica que no es indiferente la elección de una «muestra» dentro de la serie $(t, t+k)$ para determinar las características de la misma. Un tipo de series estacionarias es el llamado «proceso puramente aleatorio» o «ruido blanco», y que se define por:

$$
\begin{aligned}
& E\left(x_{t}\right)=\mu=0 \\
& \operatorname{Var}\left(x_{t}\right)=\sigma^{2} \\
& \operatorname{cov}\left(x_{p} x_{t+k}\right)=0
\end{aligned}
$$

sean cuales sean $t$ y $k$, es decir, para cualquier periodo. Al no existir tendencia y ser constante la varianza, el coeficiente de correlación de dos «ruidos blancos» ofrece la máxima confianza. Por tanto, si logramos transformar las series

${ }^{3}$ Se trata de una matriz cuadrada cuyos elementos indican el coeficiente de correlación (raiz cuadrada del coeficiente de determinación) de las series de precios de dos plazas. Por ejemplo,

\begin{tabular}{|c|c|c|c|}
\hline ' & Pamplona & Lérida & Zaragoza \\
\hline Burgos . . & 0,79 & 0,74 & 0.79 \\
\hline$\ldots \ldots \ldots \ldots \ldots \ldots \ldots \ldots$ & & 0,74 & 0,85 \\
\hline 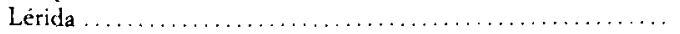 & & & 0,91 \\
\hline
\end{tabular}
para el periodo 1814-1825 los coeficientes de las series de precios del trigo de cuatro ciudades del norte de España son:

N. Sánchez-Albornoz (1975), pp. 184-219.

5 En todos los casos, los coeficientes Durbin-Watson de las regresiones construidas con series no transformadas de precios son inferiores a 1. En cambio, los coeficientes Durbin-Watson de las regresiones calculadas con las diferencias de los logaritmos de los precios son más o menos próximos a 2. Esto implica que en el cálculo de coeficientes con series no transformadas se incurre en un grave problema de autocorrelación positiva de primer grado, que es eliminado en series transformadas. Una autocorrelación tan marcada se explica por la presencia de tendencias no depuradas, que conducen a la obtención de coeficientes de determinación demasiado eleva. dos. Puede verse un caso teórico en Chevet y Saint-Amour (1991, pp. 98-99) y otro práctico en V. Barnett (1995, pp. 333-334 y 345-359. Peña Sánchez y Sánchez-Albornoz (1983, pp. 81, 91 y 99) también creen que una diferenciación y una logaritmización son necesarias en las series de precios de Valladolid y Zaragoza, pero no asi en La Coruña. 
iniciales en estacionarias, sin alterar las características que definen su relacion, podremos depositar una confianza aceptable en dicho coeficiente.

En el caso que nos ocupa, esta conversión es muy sencilla. Para lograr una varianza constante (en terminologia econométrica, «homocedástica») basta con hacer una simple transformación logarítmica de los datos iniciales. Para anular la tendencia basta con diferenciarla, es decir, construir una nueva serie en la que cada elemento sea la diferencia de dos consecutivos de la inicial ${ }^{6}$. Así, las series estacionarias reducen, e incluso anulan, la influencia de factores ajenos al de una perturbación "puntual», como el ciclo o la tendencia ${ }^{7}$.

Una vez transformada la serie inicial en otra estacionaria, podriamos calcular una matriz de coeficientes, tal y como hace Sánchez-Albornoz. Sin embargo, estas matrices no ofrecen una visión continua del proceso de formación del mercado nacional. De su lectura sólo se pueden obtener unas pocas "fotos" del grado de integración de los mercados locales en determinados periodos. La existencia de breves retrocesos o auges podría pasar inadvertida. Asimismo, el que los períodos sean verdaderamente representativos depende del buen acierto del investigador; cuando no de la suerte ${ }^{8}$. En definitiva, cualquier elección de periodos introduce un elemento de subjetividad. Por fortuna, el acceso a programas informáticos abre nuevas posibilidades. Podemos hallar el coeficiente de correlación para una ventana de datos y desplazarla a lo largo de las series. Cada coeficiente de correlación sería calculado para el mismo número de datos, rechazando en cada ocasión el primero de los empleados en el coeficiente anterior, y tomando el siguiente al último ${ }^{9}$. El resultado será una Función Cruzada de Coeficientes (en adelante, FCC).

Siendo $N$ el conjunto de datos de la serie, y $n$ los empleados en cada coeficiente, el número de valores de la FCC seria $N-n$. Por supuesto, la determinación de $n$ es arbitraria. Cuanto más bajo sea, las fluctuaciones de la función serán más intensas, pero también menos significativas. En efecto, si se produce un ascenso brusco y breve de los valores de FCC, éstos no representan una verdadera mejora de la integración de los mercados; posiblemente sean el reflejo de una crisis agraria, en la que, como es sabido, se produce una rápida

- Si con la primera diferenciación la serie no es estacionaria, se puede diferenciar de nuevo.

7 Peña y Sanchez-Albornoz (1983), pp. 29-33.

\& El problema de la no estacionariedad de las series de datos no transformados se combina con el del empleo de muestras muy grandes y de diferentes tamaños. Los coeficientes de determinación calculados con muestras muy grandes de este tipo de datos son mayores que los calculados con muestras más pequeñas, ya que incluyen tendencias más acusadas.

9 B. M. Roehner (1994), pp. 343-394. 
elevación e igualación de los precios de distintas plazas. Por ello, la elección de un valor de $n$ elevado reduce la influencia de las perturbaciones comunes e imprevisibles, aunque también la visión del proceso en períodos cortos. Quizá lo más conveniente sea construir varias FCC con distintos valores de $n$, a fin de comparar y confirmar los resultados.

El tratamiento estadístico de una FCC no es muy diferente del que puede hacerse de cualquier otra serie temporal. El estudio descriptivo (tendencia, media, varianza) proporcionaría información sobre el proceso de integración de los mercados. La construcción de otros modelos econométricos permitiria comprender qué relaciones existen entre la integración y el crecimiento de la población o el comercio exterior. La misma comparación entre los procesos de integración de varias ciudades podría realizarse sin demasiadas dificultades. Calculadas las FCC, se hallarian los coeficientes de correlación entre dos de ellas, bien para toda la muestra, bien para distintos períodos. $Y$, por supuesto, también cabria hallar la FCC de dos FCC, aunque dudo que tal refinamiento pueda ser realmente útil.

Los valores obtenidos deben ser susceptibles de comparación, y para ello ninguna época es más indicada que la actual. Hoy en día hay varias empresas de transporte - RENFE, navieras y transportistas de carretera-, excelentes medios de comunicación y un mecanismo internacional de equilibrio de mercados - montantes compensatorios de la $\mathrm{CE}$ - Cualquiera que haya sido el grado de integración de los mercados del siglo pasado, necesariamente debió ser inferior al actual. La Junta de Castilla y León publica desde 1989 los precios mensuales del trigo en las capitales de provincia de la autonomia ${ }^{10}$. Calculados los coeficientes de correlación de las series transformadas de precios de Burgos/Valladolid, Valladolid/Segovia y Burgos/Segovia, los resultados son $0,55,0,56$ y 0,73 , respectivamente. En fin, un valor de la función de 0,5 (y que implicaría un coeficiente de determinación de 0,7$)$ puede ser considerado como caracteristico de una integración más que aceptable.

\section{LOS PRECIOS DE TRIGO EN EL NORTE DE ESPAÑA}

Hace ya más de dos décadas que Gonzalo Anes ${ }^{11}$ reivindicara la utilización de mercuriales como una fuente fiable para la reconstrucción de los precios agrícolas. Dicha información no sólo es válida; además es muy abundante.

10 Información Agraria de Castilla y León, 1989.1996.

11 G. Anes Álvarez (1970), pp. 69.72. 
Muchos archivos municipales, en especial en el norte de España, contienen registros minuciosos de los precios del trigo y la cebada desde comienzos del siglo XIX, cuando no antes. Con lagunas más o menos serias, he podido reconstruir las series mensuales de precios para el periodo $1814 / 1883$ en una veintena de ciudades: Burgos, Córdoba, La Coruña, Gerona, Granada, Huesca, León, Lérida, Lorca, Medina de Rioseco, Mérida, Oviedo, Pamplona, Santander, Santiago, Segovia, Toledo, Tolosa, Tudela, Vitoria y Zaragoza. Faltan los precios de dos importantes plazas, Madrid y Barcelona, que, por su interés, he recogido en otras fuentes 12 .

Con estas 23 series de precios sería posible obtener 253 FCC diferentes ${ }^{13}$; demasiadas para ser estudiadas por separado. Afortunadamente, casi todas siguen el mismo modelo. Este es el que aparece representado en los gráficos 1 al 4, que corresponde a varias FCC construidas con 60,120 y 240 meses, y que recogen la integración entre mercados lejanos y próximos. Partiendo de unos valores muy bajos, las funciones crecen a partir del periodo $1825 / 30$, alcanzando su máximo alrededor de 1850. Con ocasión de las grandes crisis agrícolas, en $1857 / 58$ y 1868 aún habrá ligeros repuntes. Pero desde la década de los 60 se produce una declinación, que se acentúa a finales de los 70 .

12 La información de las mercuriales se ha completado con la existente en los boletines oficiales de ia provincia, en los que aparece el desglose por partidos judiciales de los precios provinciales que se registran en la Gaceta de Madrid. En todos los casos he podido comprobar que una y otra fuente son la misma; a menudo, se repiten las mismas cifras decimal a decimal. Los precios provinciales de la Gaceta de Madrid fueron recogidos por N. Sánchez-Albornoz (1975). En cierto modo, es una información superior, al abarcar una muestra mayor que los locales. Sin embargo, tienen muchos problemas. El más obvio es que sólo comprende el periodo 1856/57. 1890. Pero, además, el hecho de estar construidos sobre medias no ponderadas tiene como consecuencia que el peso de un gran municipio en el cálculo del precio provincial es el mismo que el de uno pequeño. Por otro lado, la sistemática del registro es deficiente; por ejemplo, los precios de una plaza no se recogen durante varios meses, o años; o se toman unidades de medida equivocadas; incluso se cometen errores aritméticos. Creo que una utilización «inteligente» de estos precios resuelve todos los problemas. Por ejemplo, no encuentro ningún reparo en utilizar los precios de la provincia de Madrid como precios de la capital; no asi con Asturias y Oviedo. Siempre que sea posible, es conveniente comparar el origen (boletin provincial) y el destino ( $G a$ ceta). Otras fuentes complementarias son mucho menos útiles (pan) o poco frecuentes (harina). En general, las reconstrucciones han sido mínimas. Las mercuriales tienen pocas lagunas, y las que hay, son cubiertas por los boletines provinciales. Sólo me parece pertinente señalar que: la serie de Zaragoza desde 1861 ha sido reconstruida a partir de la de Huesca y de la Gaceta. Los resultados son muy similares a los obtenidos por A. Peiró (1987) a partir de diversas publicaciones locales. Respecto a las series de precios de Barcelona y Madrid, he empleado los datos de la Gaceta de Madrid; la serie de Santander desde 1860 a 1875 ha sido reconstruida a partir de la de Torrelavega y de la Gaceta.

${ }_{13}$ El número de combinaciones posibles de $N$ series de precios es $N \times(N-1) / 2$. 


\section{GRÁFICO 1}

FCC.Santader/Medina de Rioseco

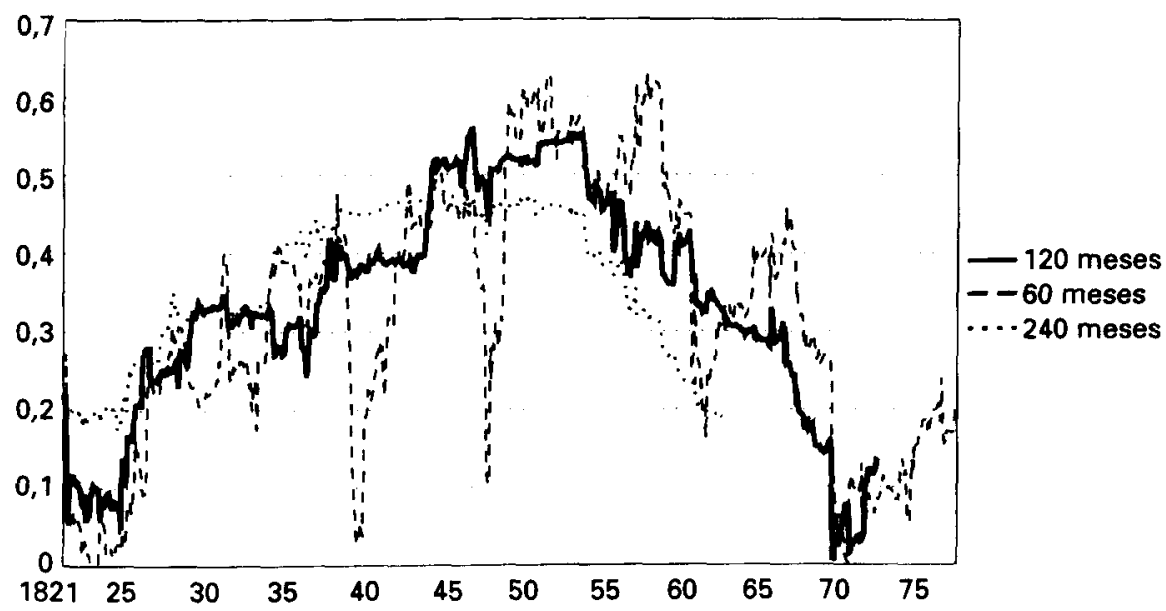

FuENTE: Mercuriales (véase texto).

\section{GRÁFICO 2}

FCC Zaragoza/León

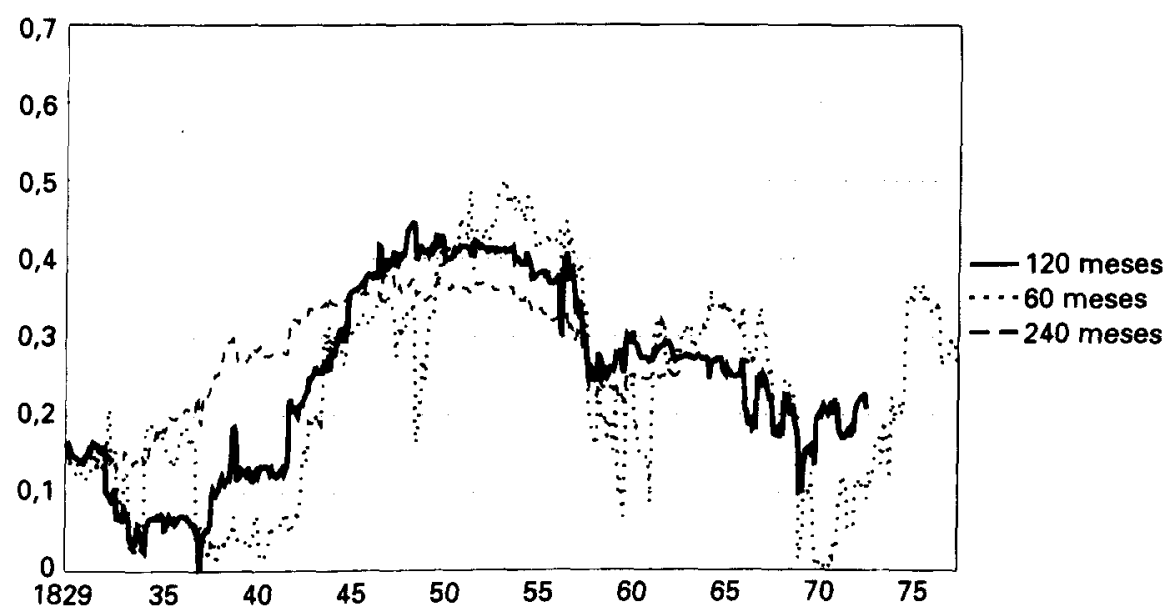

FuENTE: Mercuriales (véase texto). 


\section{GRÁFICO 3}

FCC Burgos/Segovia

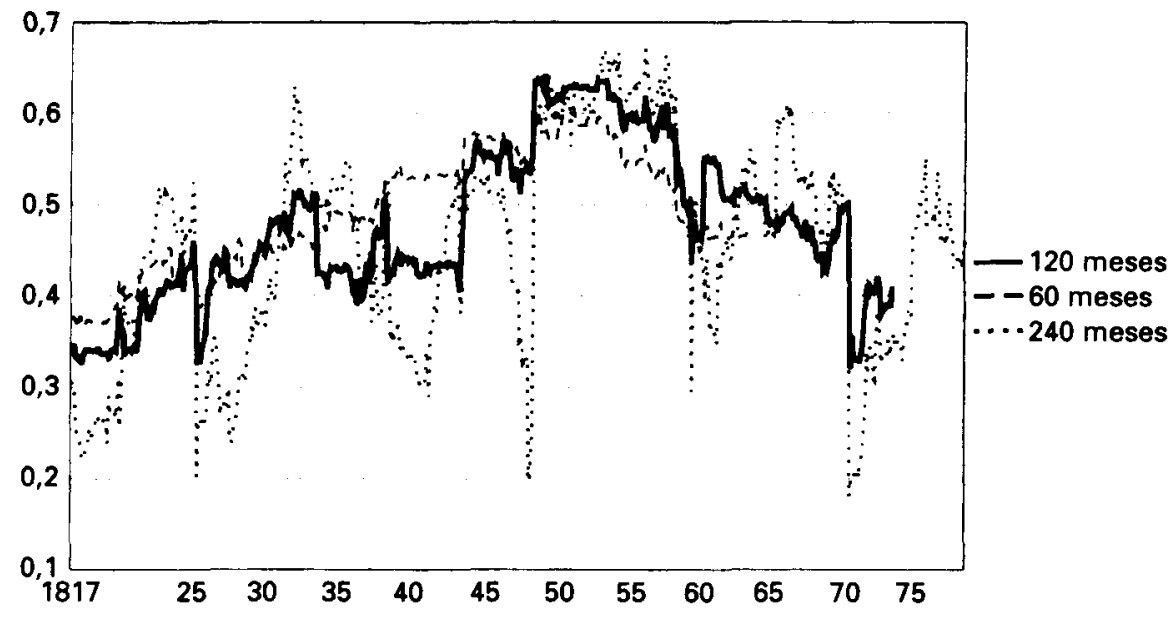

Fuente: Mercuriales (véase texto).

\section{GRAFICO 4}

FCC La Coruña/Medina de Rioseco

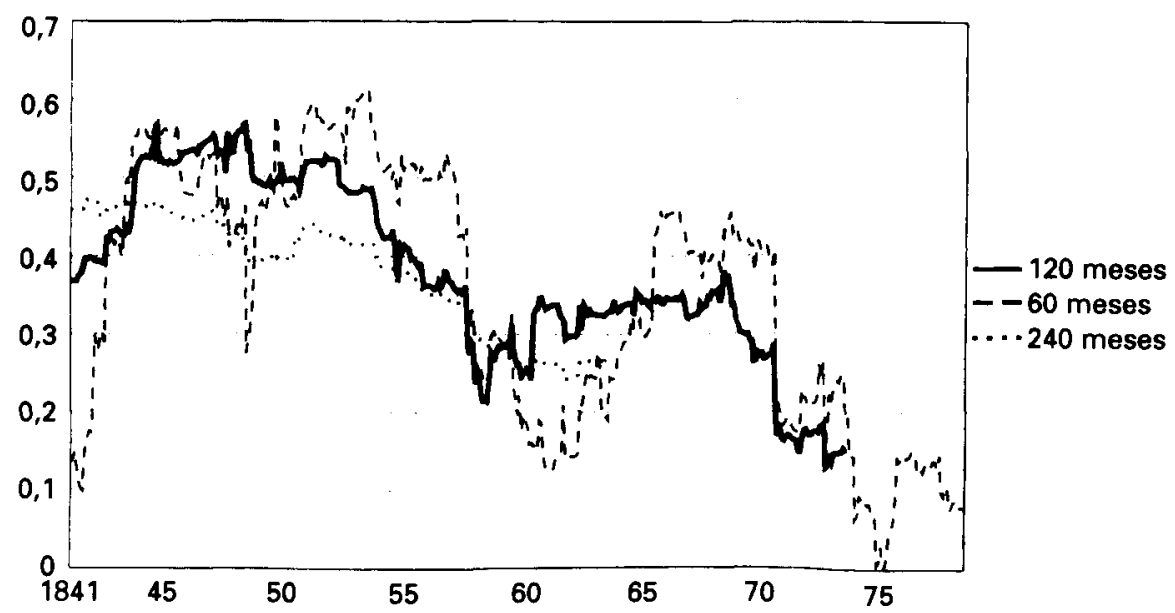

Fulnte: Mercuriales (véase texto). 


\section{GRÁFICO 5}

FCC de Barcelona con Medina de Rioseco y Zaragoza

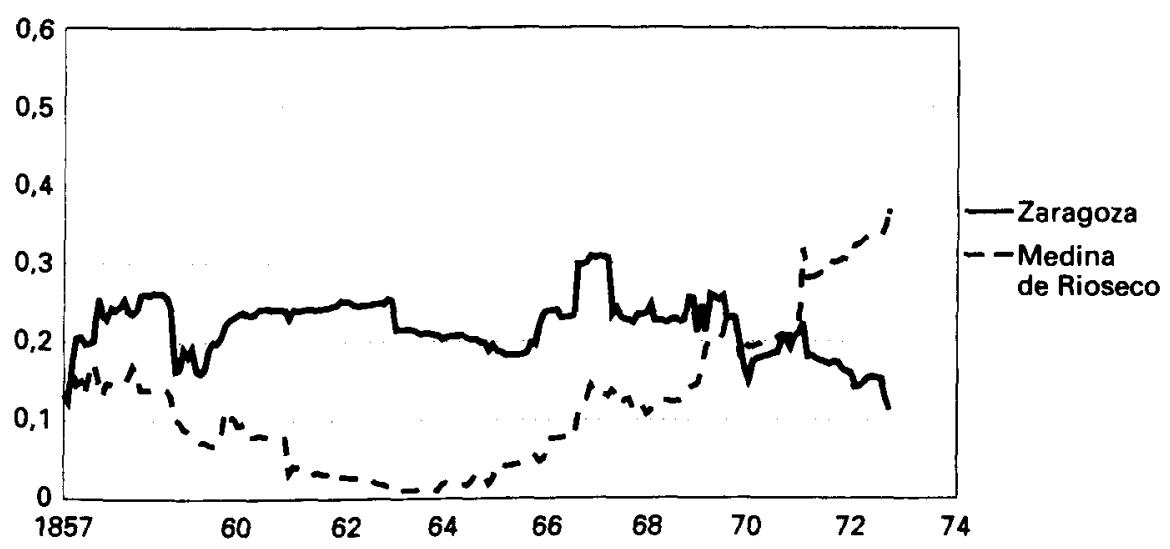

120 meses

FUENTE: Mercurial y Sánchez-Albornoz (1975, pp. 71 y 111 ) (véase texto).

GRÁFICO 6

FCC de Madrid con Medina de Rioseco y Zaragoza

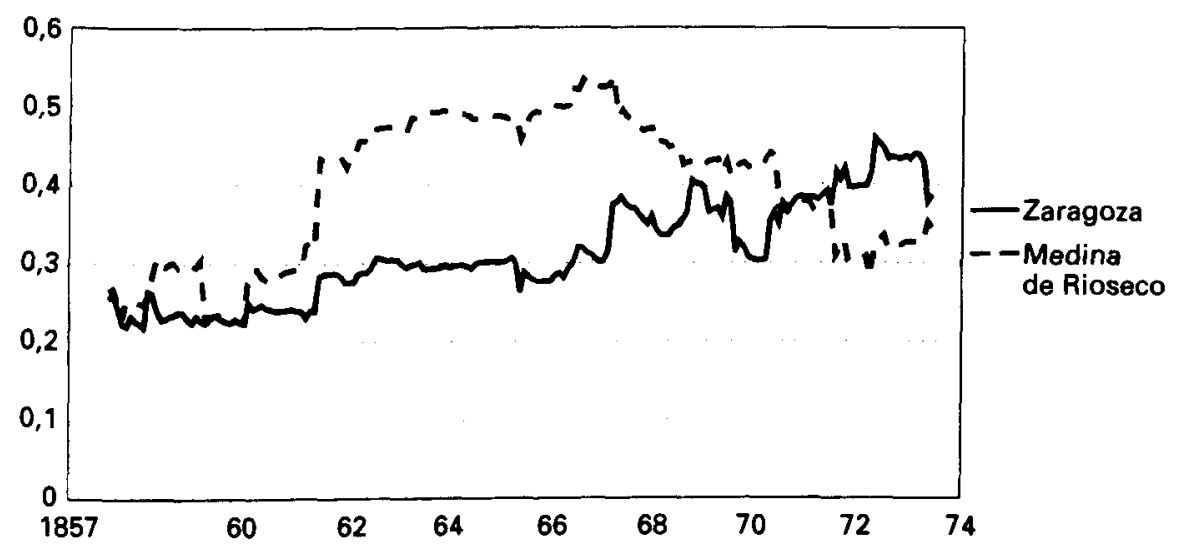

120 meses

Fuente: Mercurial y Sánchez-Albornoz (1975, pp. 91 y 111) (véase texto). 
Sobre este modelo general hay pequeñas variaciones, que parecen obedecer a circunstancias locales (como la guerra Carlista). Globalmente, el proceso de integración parece haber declinado desde los años 60. Sin embargo, al menos dos FCC - Madrid/Zaragoza y Barcelona/Medina de Rioseco- presentan un comportamiento marcadamente distinto en esos años, tal y como puede observarse en los gráficos 5 y 6. ¿Por qué?

\section{LOS FACTORES DE LA INTEGRACIÓN: LA PRODUCCIÓN AGRARIA}

La comercialización del trigo sólo es posible cuando existen excedentes; es decir, cuando la producción se sitúa por encima del consumo, siempre y cuando las diferencias de precio y renta no puedan forzarla. Hoy en día muchos trabajos confirman el auge de la producción en las primeras décadas del siglo. Bartolomé Yun Casalilla ${ }^{14}$, Gabriel Tortella Casares ${ }^{15}$, Enrique Llopis Agelán ${ }^{16}$ o Agustín Yoshiyuki Kondo ${ }^{17}$, por citar algunos nombres, ofrecen diversos indicios. Los dos últimos retrotraen esa expansión al fin de la Guerra de la Independencia; y, en consecuencia, anticipan el crecimiento de la producción agraria a la integración de los mercados en varios años.

Efectivamente, hay muchas razones para creer que desde 1814 la producción agraria estaba creciendo. La prueba más evidente es el propio crecimiento demográfico. Vicente Pérez Moreda cree que la cifra proporcionada por el censo de Godoy de 1797 - 10,5 millones de habitantes_- que no era muy distinta de la del censo de Floridablanca de 1787 - 10,4 millones-, sería similar a la de 1814. Si se aceptan los datos del censo de 1833 de 12,3 millones de habitantes (Pérez Moreda lo cree «cercano a la realidad») en el plazo de 19 años la población española se habria incrementado en un $0,9 \%$ anual ${ }^{18}$. Necesariamente hubo que producir más. Ahora bien; la integración de los mercados no se origina como consecuencia de un mero aumento de la producción, sino de un aumento de la producción comercializada, especialmente hacia las ciudades. Pues bien; creo que hay muchas razones para suponer que el volumen de trigo comercializado con anterioridad a 1830 fue bastante pequeño.

A menudo se ha argüido que la legislación prohibicionista de 1820 contri-

\footnotetext{
14 B. Yun Casalilla (1987), pp. 629-636.

15 G. Tortella Casares (1985), pp. 63-88.

16 E. Llopis Agelán (1985), pp. 129-150.

17 A. Y. Kondo (1990), pp. 17-32.

18 V. Pérez Moreda (1985), pp. 25-31.
} 
buyó a articular el mercado nacional. Las ciudades que hasta entonces se abastecian en el exterior, empezarían a hacerlo en Castilla, permitiendo una mayor conexión entre los mercados. Creo que la realidad fue muy diferente. En contra de lo que se suele decir, España no dejó de importar grano a partir de 1820. De forma legal o ilegal, el trigo siguió llegando a los mercados mediterráneos. Josep M. Fradera ha contado los barcos procedentes del Atlántico Norte español y del extranjero que atracaron en Barcelona con cereales desde 1821 a $1830^{19}$. Dada la prohibición, es imposible saber qué cantidad de trigo se desembarcó de los segundos de forma ilegal. En todo caso, hasta 1827 los barcos españoles apenas sobrepasan los cuarenta, siendo dos, cuatro y hasta siete veces más los barcos extranjeros que recalaron. En estos años, la misma legislación arancelaria es suspendida en varias ocasiones, lo que permite al Diario de Barcelona recoger los precios del trigo de Ancona, Odessa o Londres de forma bastante continua hasta abril de 1826. Esto tampoco quiere decir que desde entonces sólo se comprara trigo español. Una parte del consumo de la ciudad condal debió proceder del contrabando, especialmente a través de Mallorca. El gobierno dispuso varias normas para luchar contra él en 1824, $1826,1828,1834,1835$ y 1839 . La Junta de Comercio de Barcelona y el Intendente de la Provincia de Gerona todavía suponian la entrada de grano en 1837 y $1838{ }^{20}$.

El otro gran mercado de las harinas castellanas confirma esta imagen. E1 arancel restrictivo de 1818 no se pudo aplicar en Cuba hasta 1824. A pesar de la discriminación efectuada a las harinas americanas, éstas siguieron dominando sobre las españolas hasta 1829. En 1830 se impuso un arancel aún más duro, lo que proporcionó un breve reinado a las harinas castellanas. Pero un régimen más permisivo en 1831 hizo que hasta 1837 las harinas norteamericanas volvieran a ser más numerosas ${ }^{21}$. En fin, no parece que en la década de los 20 , e incluso durante los primeros 30 , Castilla dispusiera de grandes excedentes que vender.

El movimiento interno de los trigos repite lo descrito para el comercio de cabotaje. Durante el siglo xvill el mercado de Tolosa se proveyó de trigo alavés y navarro. Pero acabada la Guerra de la Independencia, dichos granos no volvieron hasta octubre de 1829.

Los datos decimales también son muy reveladores. A partir de ellos, y para el período 1780-1835, Laureano Rubio Pérez ha calculado la producción del

\footnotetext{
19 J. M.* Fradera Barceló (1984), pp. 161-162. También (1987), pp. 109-111.

20 J. M." Fradera Barceló (1987), pp. 116-117.

21 J. Moreno Lázaro (1995), pp. 232-233.
} 
trigo en varios pueblos del norte de León y Palencia ${ }^{22}$. No hace falta insistir sobre los problemas de dicha fuente; pero ocurre que el noroeste peninsular es una zona de baja resistencia al pago, y por tanto, de elevada fiabilidad. De la información obtenida se desprende que la producción de los primeros años del siglo XIX es muy inferior a la de los años 80 o 90 del siglo anterior. Pero en lo que me interesa detenerme es en la evolución en el siglo XIX, que presento, para todos los pueblos, en el cuadro 1. Las últimas cifras no son significativas, ya que falta información de muchos pueblos, que seguramente dejaron de pagar el diezmo. Las bajas cifras de la Guerra de la Independencia y del Trienio Liberal se explican por los acontecimientos políticos, las crisis y la turbulenta evolución de la percepción decimal. A lo largo del periodo contemplado no se aprecia un incremento de la producción. Pueblo a pueblo, sí que se puede observar, pero son los menos, y no son crecimientos enormes. Gonzalo Anes ofrece cifras semejantes, aunque menos detalladas, para Asturias ${ }^{23}$. En fin, en esta área (aunque no en otras) el mismo aumento de la producción por habitante resulta discutible.

CUADRO 1

Producción de trigo en el norte de León y Palencia

\begin{tabular}{|c|c|c|c|c|c|c|}
\hline & $A \tilde{n o}$ & $\begin{array}{c}\text { En miles } \\
\text { de } Q m \text {. }\end{array}$ & Año & $\begin{array}{c}\text { En miles } \\
\text { de Qm. }\end{array}$ & Año & $\begin{array}{c}\text { En miles } \\
\text { de Qm. }\end{array}$ \\
\hline 1808 & & 37,7 & 1819 & 54,0 & 1830 & 45,2 \\
\hline 1809 & & 42,2 & $1820 \ldots$ & 38,0 & $1831 \ldots$ & 23,9 \\
\hline 1810 & & 25,2 & $1821 \ldots \ldots \ldots \ldots$ & 14,5 & $1832 \ldots$ & 35,1 \\
\hline 1811 & $\ldots$ & 19,1 & $1822 \ldots \ldots \ldots \ldots$ & 17,6 & 1833. & 12,8 \\
\hline 1812 & $\ldots$ & 35,5 & $1823 \ldots \ldots \ldots \ldots$ & 50,8 & 1834. & 16,2 \\
\hline 1813 & & 52,3 & $1824 \ldots \ldots \ldots \ldots$ & 50,7 & 1835. & 37,8 \\
\hline 1814 & $\ldots \ldots \ldots \ldots$ & 45,8 & 1825. & 50,9 & 1836. & 18,9 \\
\hline 1815 & $\ldots \ldots \ldots \ldots$ & 49,6 & ............. & 52,6 & $1837 \ldots \ldots \ldots \ldots$ & 7,1 \\
\hline 1816 & $\ldots \ldots \ldots \ldots$ & 59,5 & $1827 \ldots \ldots \ldots \ldots$ & 33,9 & $1838 \ldots \ldots \ldots \ldots$ & 9,2 \\
\hline 1817 & $\ldots \ldots \ldots \ldots$ & 50,0 & $1828 \ldots \ldots \ldots \ldots$ & 40,1 & & \\
\hline 1818 & ............ & 39,6 & 1829. & 60,5 & & \\
\hline
\end{tabular}

FUENTE: Laureano Rubio (1986, p. 44).

22 L. M. Rubio Pérez (1986), p. 44.

23 G. Anes Álvarez (1988), pp. 64-66. 
También Gonzalo Anes ha estimado la producción de trigo a partir de varias estadísticas generales de cosechas de 1791, 1797 y 1818. Aunque falta la información de muchas provincias, se puede obtener una imagen de su producción a partir de la comparación con otras. En resumen, la producción de trigo de 1818 fue un $20 \%$ y un $15 \%$ inferior a las de 1791 y 179724 . A tenor de los bajos precios de ese año, no hay razón para suponer que hubiera una crisis agrícola. Con tal déficit, ¿cómo podrian mantenerse grandes flujos comerciales?

Hay otros muchos indicios. Bartolomé Yun Casalilla 25 cree probable una expansión de las roturaciones, y de la producción agrícola, en los años siguientes a la Guerra de la Independencia en la comarca de Tierra de Campos. Pero es revelador que esa expansión se deba a la emigración desde la montaña a la llanura. Los índices de Pérez Picazo ${ }^{26}$, de Garrabou, Pujol y Colomé 27 y de Reher y Ballesteros ${ }^{28}$ muestran cómo los salarios reales de este período apenas se mantuvieron; e incluso cayeron en las áreas rurales. Ello es compatible con un aumento de la producción por crecimiento vegetativo; pero no lo es si la causa de ese aumento fuera una mayor comercialización. En fin, la propia caída de los precios agrícolas es muy significativa. Evidentemente, el que los precios suban o bajen poco tiene que ver con un aumento de la producción como consecuencia del aumento demográfico. Pero no ocurre lo mismo con la producción destinada a la comercialización ${ }^{29}$.

En resumen, a partir de 1814 , y una vez superadas las grandes crisis del paso del siglo, la agricultura española entró en un período de expansión. Sin embargo, los bajos niveles de partida y el elevado crecimiento demográfico

24 G. Anes Alvarez (1970), pp. 147-150. He calculado la producción de 1791, 1797 y 1818 en $14.090,13.200$ y 11.274 miles de Qm, a los que habria que añadir medio millón más cosechados en Navarra, Vizcaya, Guipúzcoa y Galicia.

23 B. Yun Casalilla (1987), pp. 629-636.

26 M." T. Pérez Picazo (1990), p. 259-260.

27 Garrabou, Pujol y Colomé (1991), p. 46.

${ }_{28}$ Reher y Ballesteros (1993), p. 134-135.

${ }_{29}$ A. Garcia Sanz (1985, pp. 79-80) hace una lectura muy distinta. En su opinión, los campesinos no actuaban de acuerdo a criterios capitalistas, por lo que un descenso de los precios no puede ser interpretado como un estancamiento o retroceso de la agricultura. Al contrario, tratarian de compensar sus ingresos incrementando la producción mediante un empleo más intensivo de los miembros de la unidad familiar. Esto parece poco creible. Si los campesinos no operaban con criterios capitalistas en el siglo XIX, tampoco debieron hacerlo anteriormente; y ello no impidió que todas las expansiones agrícolas fueron acompañadas de aumentos de los precios, así como las depresiones de descensos (véase, por ejemplo, B. H. Slicher van Bath (1978), pp. 289. 326). Tampoco parece posible incrementar la producción por una intensificación del trabajo de los miembros de la unidad familiar; el factor limitativo de la producción no era el trabajo, sino la tierra. 
mantuvieron el consumo muy bajo. Como tantas otras veces cuando los tiempos son malos, la reacción de los ayuntamientos consistió en mantener grandes reservas, lo que llevó al Gobierno a promulgar en tres ocasiones distintas la libertad de comercio. Por razones muy distintas, también se prohibió la importación de granos. Sin embargo, por sí solas estas medidas hubieran tenido poco efecto. La ley de 1820 fue sistemáticamente suspendida o ignorada. Los bajos precios, los acopios municipales, el mantenimiento del diezmo y las mismas perturbaciones políticas impidieron una reactivación del comercio del trigo. Sólo a partir de las buenas cosechas de 1828,1829 y 1830 las cosas empezaron a cambiar. El decreto de 1824 se conjugó con la rebelión a los diezmos y la quiebra final del régimen. Las roturaciones espontáneas que precedieron a la desamortización de Mendizábal permitieron un aumento de la superficie de cultivo. Cuando el régimen fernandino cayó, el sector agrario ya habia empezado a caminar hacia el mercado.

\section{LOS FACTORES DE LA INTEGRACIÓN: LA CARRETERÍA}

La creciente integración de los mercados entre 1825 y 1850 es incompatible con algunas de las hipótesis formuladas por David Ringrose sobre el sistema de transporte tradicional. En su obra más conocida ${ }^{30}$, señala que la mayor parte de los acarreos eran realizados por agricultores en los períodos de menor actividad agricola y mejor tiempo. Un transporte de estas características tenía la ventaja de ser muy barato, pero ofrecía muchos inconvenientes, ya que la oferta se encontraba limitada; en primer lugar, por la estacionalidad. Así, en Castilla, esta actividad se veía restringida a unos pocos meses, ya que el frío y la lluvia la imposibilitaban en diciembre y enero; la falta de pastos en agosto, septiembre y octubre; las ocupaciones de la labranza en enero, febrero y marzo; y las de la siega en junio y julio; con lo que sólo en abril, mayo y noviembre habria habido ocasión para realizarla. Incluso los carreteros profesionales debían limitar su actividad a los meses de clima no demasiado extremo. Por otro lado, Ringrose cree que los cambios institucionales que se inauguran con el cambio de siglo ocasionaron una reducción de los servicios de transporte. El cercamiento de tierras, el declive de la Mesta y las leyes desamortizadoras redujeron la disponibilidad de pastos, con lo que los carreteros vieron limitadas sus posibilidades de desplazarse a largas distancias. Por tanto, el ferrocarril en-

\footnotetext{
30 D. Ringrose (1972).
} 
cuentra una competencia muy debilitada; y en este sentido viene a cubrir un hueco en la economía española.

Antonio Gómez Mendoza comparte esta visión negativa del sistema de trasporte tradicional, al suponerlo precario, caro e incapaz de articular los mercados ${ }^{31}$. Por tanto, no es extraño que el ferrocarril permitiera una rebaja del precio de los portes y la construcción de un mercado nacional ${ }^{32}$. Esta conclusión se deriva (al menos en parte) del cálculo del «ahorro social» que supondria la construcción de la red ferroviaria. Este cálculo exige conocer el coste medio de los distintos medios de transporte. Para 1878, y sobre los datos de la Compañía de ferrocarriles del Norte, Gómez Mendoza estima que el precio medio del transporte por ferrocarril fue de $0,08537 \mathrm{ptas} / \mathrm{ton} / \mathrm{km}$ (pesetas por tonelada y kilómetro). El sistema de transporte tradicional tenía un coste más variable, según lo efectuasen los propios campesinos $(0,144 \mathrm{ptas} / \mathrm{ton} / \mathrm{km})$, las carretas $(0,625 \mathrm{ptas} / \mathrm{ton} / \mathrm{km})$ o las bestias de carga $(1,08 \mathrm{ptas} / \mathrm{ton} / \mathrm{km})$. Un coste medio del transporte podría ser de $0,8234 \mathrm{ptas} / \mathrm{ton} / \mathrm{km}^{33}$.

$\mathrm{La}$ tesis que trato de defender no niega que el transporte pudiera ser tan caro como han descrito Ringrose y Gómez Mendoza. Ahora bien, bajo determinadas circunstancias, que nada tenían de especial, el transporte del trigo podía ser extremadamente barato. Sin duda, más que del transporte del siglo XIX, habría que hablar de «los transportes» del siglo XIX.

No es una tesis nueva. Santos Madrazo, a partir de cuatro casos distintos, estima que el coste del transporte del trigo a mediados de siglo era de 0,41 $\mathrm{ptas} / \mathrm{ton} / \mathrm{km}$. Dicho cálculo es la media del precio en cuatro trayectos difíciles, que enlazaban la costa con la meseta peninsular. Tres de ellos lo son en sentido ascendente —en concreto, Cádiz-Cáceres, Málaga-Jaén y Alicante-Albacete-, cuando lo habitual era que el trigo fluyese del interior a la costa. El cuarto es León-Gijón. Precisamente el trayecto más largo, y que proporcionalmente es el que tiene una pendiente menor, Cádiz-Cáceres, se efectúa al precio de $0,28 \mathrm{ptas} / \mathrm{ton} / \mathrm{km}^{34}$.

Pero, sin duda, el recorrido más interesante en esta época es el camino de Reinosa, que enlazaba la gran región productora de Castilla con el puerto de Santander. Las noticias que tenemos sobre esta vía son especialmente numerosas. Andrés Hoyo Aparicio ${ }^{35}$ y Ramón Garrabou y Jesús Sanz ${ }^{36}$ han estudiado

\footnotetext{
31 A. Gómez Mendoza (1989), pp. 200.

32 A. Gómez Mendoza. (1989), pp. 185.

33 A. Gómez Mendoza (1982), pp. 259-260.

34 S. Madrazo Madrazo (1984), pp. 749.

35 A. Hoyo Aparicio (1993), pp. 62-66 y 285.

36 Garrabou y Sanz (1985), pp. 46-49.
} 
su evolución. Pero el primero lo presenta como «factor-flete» (cociente entre el precio del transporte y el precio de la mercancia) y el segundo recoge una muestra relativamente pequeña. Además, Andrés Hoyo y yo mismo hemos encontrado algunas informaciones nuevas. Con todas estas noticias, nuevas y viejas, he reconstruido el cuadro 2 :

\section{CUADRO 2}

Estimaciones coetáneas del precio del transporte

\begin{tabular}{|c|c|c|c|c|}
\hline Año & Fuente & Precio & $\begin{array}{l}\text { Origen/ } \\
\text { Destino }\end{array}$ & Observaciones \\
\hline $1831 \ldots$. & Sierra & $0,35 / 0,57$ & Reinosa & Sin y con espolvoreo \\
\hline Guerra & Sierra & 0,73 & Palencia & Precio máximo \\
\hline $1839 \ldots \ldots$ & Comision & 0,41 & Alar del Rey & Precio proyectado \\
\hline 1839 & Alegre & 0,27 & Valladolid & Precio proyectado \\
\hline 1845 & Sierra & 0,46 & Palencia & \\
\hline $1847 \ldots$ & Dictamen & 0,36 & Valladolid & \\
\hline $1848 / 50$ & Boletin & 0,31 & Valladolid & Transporte de retorno \\
\hline $1849 \ldots$ & D. Montañés & 0,47 & Alar del Rey & \\
\hline Mediado & Laroche & 0,53 & Alar del Rey & Precio indirecto \\
\hline $1852 \ldots \ldots$ & Heras & 0,30 & Valladolid & \\
\hline 1853 & Ferrer & 0,36 & Herrera & \\
\hline 1854 & Boletín & 0,25 & Valladolid & Transporte de retorno \\
\hline
\end{tabular}

Fuente: Andrés Hoyo Aparicio (1996) (s. p.), Ramón Garrabou (1985), Boletín Oficial de Comercio de Santander y Despertador Montañés (25/3/1849).

Tal y como entonces señalaron Hoyo Aparicio y Garrabou y Sanz, existe una lenta, aunque constante, disminución del precio del porte a lo largo del segundo cuarto de siglo. Por otro lado, la diferencia de precios entre Valladolid y Herrera, Alar del Rey y Reinosa, parece señalar que el precio del transporte en terreno montañoso era bastante más elevado que en terreno llano, reduciéndose en el trayecto Valladolid-Santander por efecto del Canal de Castilla.

Sin embargo, esta conclusión debe ser revisada. Una de las fuentes nuevas es el Boletín de Comercio de Santander de 1848, 1849, 1850 y 1854. En aquellos años, el periódico cántabro era poco más que una gran «tabla de números», con los precios de las mercancias, de los fletes y de los portes. Estos últi- 
mos siempre eran los de frutos coloniales (fundamentalmente, cacao y azúcar) en dirección hacia varias plazas del interior. Por el sentido ascendente de la marcha, y por el valor de los productos, se podrian esperar costes superiores a los del transporte del trigo. Igualmente, y por el «efecto Canal de Castilla», se podría esperar que los transportes a Valladolid o Palencia fueran más baratos que los efectuados a León, Burgos o Logroño. Pues bien; el porte más barato es el de Santander-Alar del Rey, con 0,22 ptas/ton $/ \mathrm{km}$. Los portes a León y Burgos son más elevados que a Valladolid o Palencia; pero no asi el de Logroño. Además, para este cálculo se ha seguido la carretera de La Rioja, más difícil y corta que la de Reinosa.

\section{CUADRO 3}

Transporte de frutos coloniales

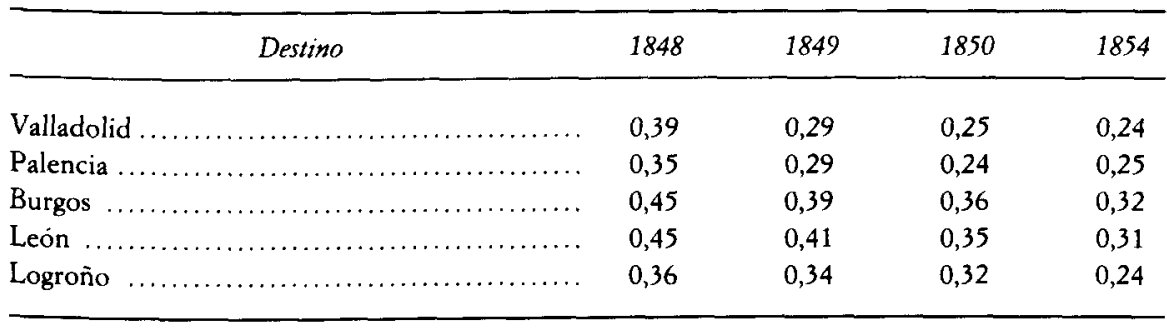

FUENTE: Boletin Oficial de Comercio de Santander.

La explicación a estas paradojas se encuentra en la mayor o menor oferta de transporte. En el mismo Boletín Oficial de Comercio de Santander aparecen cuatro estadísticas acerca de las carretas de todo tipo que atravesaron el portazgo de Peñacastillo entre marzo y junio de 1854 . De las 70.000 registradas (una cifra harto notable) sólo 42.000 iban cargadas. La conclusión obvia es que cerca de 35.000 carretas transportaron trigo a Santander, y sólo 7.000 de ellas hicieron el viaje de retorno con alguna carga, presumiblemente frutos coloniales ${ }^{37}$. $\mathrm{Al}$ existir una gran oferta de transporte de retorno, muchas carretas estaban dispuestas a hacer el trayecto a un precio muy bajo, sencillamente porque sus gastos eran casi nulos. Esto explica que ningún precio sea más barato que el de retorno entre Santander-Alar del Rey, ya que, por razones obvias, casi 1854.

${ }^{37}$ Boletín Oficial de Comercio de Santander, 10 de abril, 3 de mayo, 14 de junio y 5 de julio de 
todas las carretas que volvian de vacío debían ser montañesas. E implica que los costes del transporte del trigo aún hubieran sido menores de haber existido mayores retornos.

Respecto al bajo porte de Logroño, no parece casual que no sólo se recoja el de la capital riojana, sino también los de Haro, Najera, Calahorra, Arnedo y Mendigorria. Lo más probable es que la carreteria haya abaratado el coste en ese trayecto por medio del retorno del vino. Esta posibilidad estaba cerrada en Burgos y León, ciudades que tenían pocos artículos que ofrecer a Santander. $\mathrm{Y}$, sin embargo, incluso en ellas el precio del transporte no era demasiado alto. $\mathrm{Y}$ menores aún eran las diferencias con otras plazas, como Madrid, Medina del Campo, Zaragoza... Cabe preguntarse hasta qué punto el Canal de Castilla supuso una verdadera rebaja en el precio del transporte. O dicho de otra manera, ¿el transporte por carreta era mucho más caro que el realizado por el Canal?

En el apéndice de la ya muy conocida «Cuestión de harinas» de 1845 , se ofrece la siguiente pregunta y respuesta entre la Comisión del Ayuntamiento y Luis M.a Sierra:

Pregunta $25^{a}$ ¿De qué modo influye la no conclusión del Canal en que no sea éste el exclusivo medio de conducción?

Respuesta: Porque demora los arrastres y expone a cambios de efectos. El último inconveniente cesaría si llegase a Golmir, porque habría alli que le evitara.

Por Golmir, Sierra se refiere a Bolmir, en las proximidades de Reinosa. El Canal nunca iría más lejos de Alar del Rey, así que el problema indicado nunca se resolvería. Si una parte del transporte del trigo y la harina se efectuaba por carretas y otra por el Canal de Castilla, la diferencia entre el precio de uno y otro medio no podía ser muy grande. $Y$, de hecho, la política de tarifas practicada por la Compañia del Canal tenía mucho más que ver con la competencia con las carretas que con ningún otro factor. Entre 1841 y 1860 en vía ascendente era de un maravedí y medio por arroba y legua $-0,172$ $\mathrm{ptas} / \mathrm{ton} / \mathrm{km}$ - entre noviembre y abril; es decir, cuando el mal tiempo dificultaba (que no impedía) el transporte por carreta entre la costa y la meseta. También en vía ascendente, pero entre mayo y octubre, era de un maravedí $-0,115 \mathrm{ptas} / \mathrm{ton} / \mathrm{km}-$. Y en via descendente, compitiendo con una oferta excendentaria de carretas, 0,75 maravedies $-0,086 \mathrm{ptas} / \mathrm{ton} / \mathrm{km}-{ }^{38}$. El precio de la carreteria en el trayecto Valladolid-Alar del Rey no sería mucho mayor.

${ }^{38}$ J. Helguera Quijada (1988), pp. 116 y 132. 
Esas condiciones óptimas -elevada oferta de transporte y existencia de retornos- no tuvieron por qué ser raras. En los gráficos 7 y 8 aparecen las diferencias en el precio del trigo entre Medina de Rioseco y Santander y Pamplona y Tolosa, reducidas a ptas $/ \mathrm{ton} / \mathrm{km}$. Estas últimas se han obtenido a partir del precio del «trigo de Navarra» del archivo tolosano. Todos los precios son al por menor, por lo que si el beneficio que percibe el minorista en ambas plazas fuera constante e idéntico, la diferencia entre uno y otro sería exactamente el coste del transporte, en el que se incluiria tanto el transporte en sentido estricto como la intermediación de los mayoristas. Pero es más probable que el beneficio del minorista fuera superior en las plazas costeras, dado el mayor precio del trigo, por lo que cabe suponer que estos cálculos están hechos por exceso.

Las diferencias de precio se ven agrandadas en los años de grandes exportaciones, o en los anteriores a las crisis agrarias (que suelen ser los mismos), en los cuales el alza de los precios no afecta proporcionalmente a las plazas costeras e interiores. Por supuesto, en las grandes crisis la mayor variabilidad de los precios interiores tiene un efecto contrario, hasta el extremo de que en unos pocos meses esa diferencia se hace negativa. En fin, la suma del coste de transporte e intermediación vendria dada por la diferencia de precios en años «normales»; y en ellos, esas diferencias oscilan entre 0,3 y $0,5 \mathrm{ptas} / \mathrm{ton} / \mathrm{km}$ para Santander-Medina de Rioseco, y entre 0,2 y $0,45 \mathrm{ptas} / \mathrm{ton} / \mathrm{km}$ para Tolosa-Pamplona. Ambos trayectos son de montaña y el tráfico de trigos es frecuente. Conclusiones similares se obtienen al comparar los precios de Zaragoza y Barcelona y Albacete y Murcia.

¿Cuál podría ser el coste del transporte del trigo en España en carreta en el siglo XIX? No existe una respuesta única. Entre otros factores, ese precio dependia de las condiciones orograficas, de la oferta de transporte y de la existencia o no de retornos. Lo más que podemos afirmar es que, en condiciones óptimas, podría ser de $0,25 \mathrm{ptas} / \mathrm{ton} / \mathrm{km}$ en terreno llano, y de $0,35 \mathrm{ptas} / \mathrm{ton} / \mathrm{km}$ en terreno montañoso. Ni la estimación de Gómez Mendoza ni ninguna otra puede aplicarse de forma general. De hecho, aquella fue obtenida para un producto muy concreto, el del vino, y como media ponderada de varios tipos de transporte. Si de acuerdo a un informe de 1848 , citado por el propio Gómez Mendoza, el transporte del vino era un $46 \%$ más elevado que el del trigo ${ }^{39}$; si sólo consideramos el transporte por carretas, y si descontamos el efecto de la inflación, ese coste se queda en $0,38 \mathrm{ptas} / \mathrm{ton} / \mathrm{km}$.

39 A. Gómez Mendoza (1982), p. 90. 


\section{GRÁFICO 7}

Coste del transporte del trigo entre Medina de Rioseco y Santander

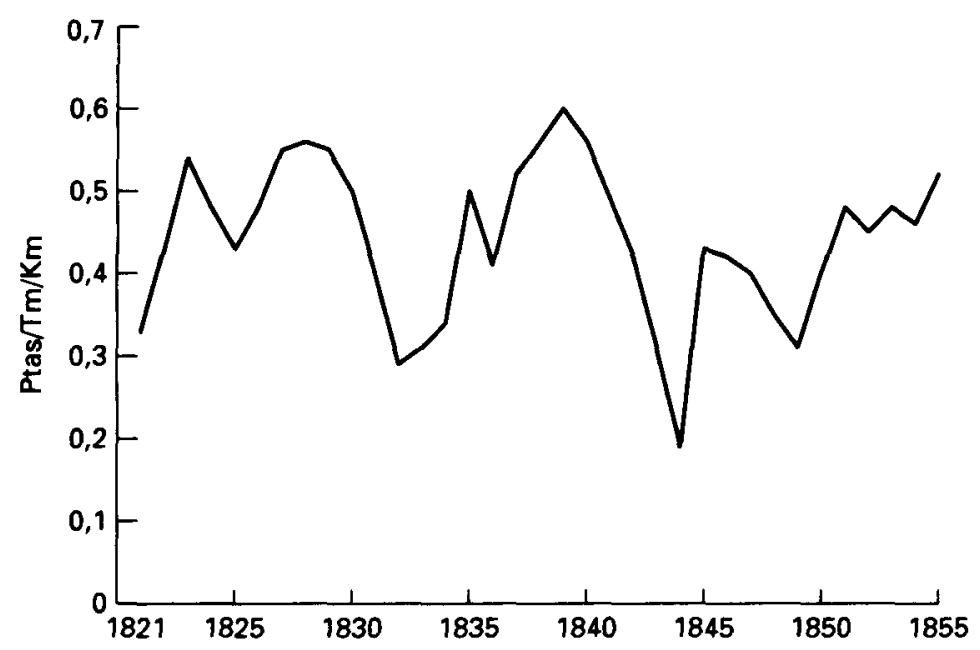

Fuente: Mercuriales (vease texto).

\section{GRÁFICO 8}

Coste del transporte del trigo entre Pamplona y Tolosa

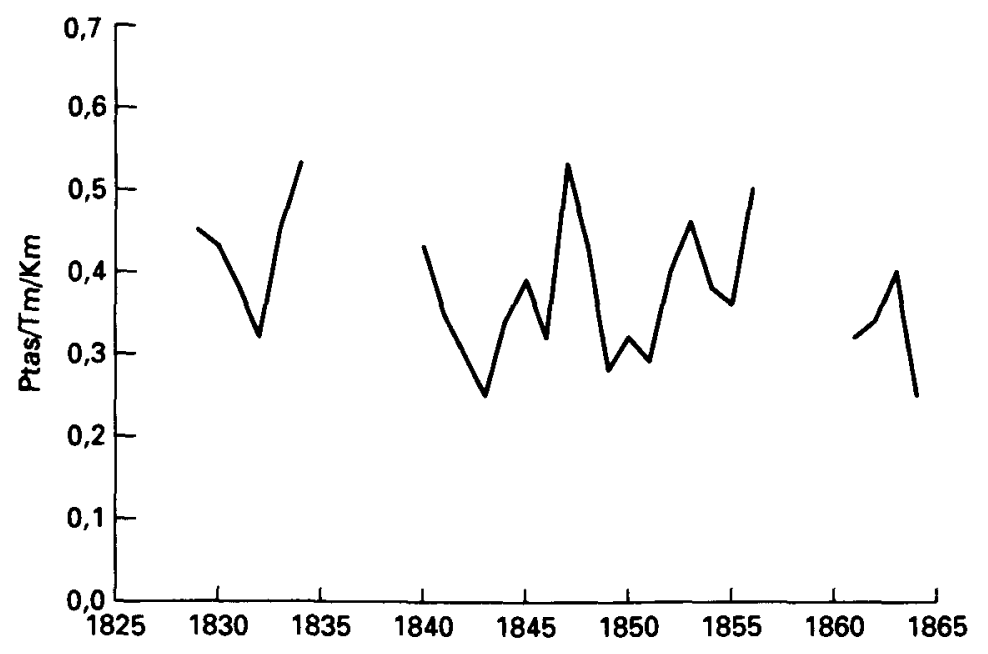

Fuinlt: Mercuriales (véase texto). 
En los decretos del 8 de junio de 1813, 26 de febrero de 1824 y 20 de enero de 1834 , los distintos gobiernos liberales y absolutistas consagraron el principio de libertad de comercio como norma juridica. Desde entonces, el transporte se configuró como un sector libre y abierto, capaz de adaptarse a las exigencias de otros sectores productivos y capaz de aprovecharse de las oportunidades que le ofrecía una economía en expansión. Por supuesto, una simple reforma legal no podía tener mayores efectos sobre el coste del transporte. Pero en los años 30 y 40 , el mismo crecimiento de los intercambios comerciales posibilitaba su rebaja simplemente por el aumento de la oferta de transporte y la existencia de retornos. Cualquiera que dispusiese de una carreta podía transportar para sí o para otro trigo, ladrillos o vino a Santander; y traer de regreso café, telas o azúcar. Esta es la principal causa del descenso de costes de la carretería a lo largo de la primera mitad del siglo.

La principal, pero no la única. Tímidamente al principio, pero con más intensidad en los años 40 y 50, el Gobierno fue tomando varias decisiones concernientes al transporte, que contribuyeron a mejorar las comunicaciones. La privatización del Canal de Castilla, en cuyo acuerdo se exigía la ampliación del mismo, fue una de ellas; aunque, tal y como hemos visto, de menos trascendencia de lo que se ha supuesto. La inversión en carreteras fue muy baja en los años 20 y 30 debido a la crisis fiscal del Antiguo Régimen y a las exigencias de la Guerra Carlista. Lo gastado anualmente entre 1814 y 1841 no debió superar los siete millones de reales, dedicados, en su mayor parte, a reparaciones, conservación y pago de intereses. Apenas se lograron construir unos 50 kilómetros anuales de nuevas carreteras hasta 1840. Pero desde entonces y hasta 1847 la cantidad media pudo llegar a los doce millones, que, además, fueron mejor invertidos. A esto habria que añadir lo presupuestado para las carreteras de Las Cabrillas y de Vigo. Un nuevo impulso tiene lugar en ese año; hasta 1854 las inversiones pudieron llegar a los 50 millones anuales. $Y$, desde entonces, esta partida se dispara. Entre 1840 y 1856 el ritmo de construcción llegó a los 300 kilómetros anuales. Cifras que se quedarán cortas en los años siguientes ${ }^{40}$.

Asimismo, una fiscalidad más ventajosa también debió contribuir a la rebaja del transporte por carretera. Según Santos Madrazo, para el conjunto de la nación y para el tipo de transporte más frecuente - la carreta-, el impacto fiscal de los portazgos supondría unas $0,07 \mathrm{ptas} / \mathrm{ton} / \mathrm{km}$. Pues bien, desde 1854 el transporte de trigo y maíz (aunque no el del propio vehículo) estuvieron exentos de dicho pago ${ }^{41}$.

40 S. Madrazo Madrazo (1984), pp. 167-176.

41 Reales Decretos de 17 de enero y de 1 de abril de 1854. 
La propia carretería contribuyó a esta rebaja con diversas mejoras técnicas. Santos Madrazo cree que las carretas que podian cargar hasta 2.000 kilogramos no eran extrañas a mediados de siglo. Esto implicaba duplicar la capacidad de las cargas del siglo anterior, aunque en las zonas montañosas, como Santander, la máxima carga parece haber sido de 1.000 kilogramos; con todo, bastante mayor a la de 50 años antes ${ }^{42}$.

Así pues, la carretería a mediados del siglo XIX era un sector extremadamente eficiente. Aunque no siempre podía ofrecer un servicio barato, sí lo podía hacer alli donde los tráficos eran más frecuentes; es decir, donde más necesario era que lo fueran ${ }^{43}$. Y no hay razón para pensar que, con el simple crecimiento de la actividad económica, no siguiera reduciendo sus costes. Con todo, las mismas razones que la hacian ser tan eficiente eran las que amenazaban su supervivencia. La ruptura de los flujos comerciales, laboriosamente construidos a lo largo de los años, podía encarecer gravemente sus costes. Un competidor que se hiciera con parte del mercado, tan sólo con los retornos, desbarataría todo el sistema carretil. El transporte por carretera era barato porque era libre y único. En cierto modo, era una actividad abierta, extensa y protegida con grandes barreras de entrada. Entonces vino el tren.

\section{LA LLEGADA DEL FERROCARRIL}

Tal y como hemos visto, a mediados del siglo XIX el mercado del trigo en España estaba razonablemente integrado. Sin embargo, las FCC muestran una tendencia descendente desde los años 60 , y caen a niveles mínimos hacia 1870-1880. De por sí, este hecho resulta difícil de explicar. Pero lo que le convierte en un verdadero misterio es el que esa desintegración del mercado nacional (o, mejor dicho, de la mayor parte del mercado nacional) fuera coetánea a la construcción de la red ferroviaria, En relación a su población (no digamos a su renta per cápita), España disponía de una más que aceptable red ferroviaria. Su trazado, obedeciera a la razón que sea, resolvía el principal problema del país: la conexión del interior con la costa. Precisamente, las principales zonas productoras, Castilla y León, La Mancha, Aragón y Andalucía Occidental, fueron

42 S. Madrazo Madrazo (1984), p. 398.

43 Exactamente, M. Artola (1978, p. 24), a partir de la Memoria de Obras Públicas de 1856, ha diseñado un curioso mapa en el que se recogen los principales flujos por carretera entre 1845 y 1854. Tres grandes zonas, Madrid, Levante y el triángulo Santander-Valladolid-Miranda, disfrutarían de bajos costes de transporte. Asimismo, los ejes Barcelona-Cádiz, La Coruña-Cartagena y Barcelona-Cartagena. En fin, estas líneas perfilan la futura red de ferrocarriles. 
conectadas a las principales zonas consumidoras, Madrid, Levante, Cataluña, Santander (como puerto de salida) y el País Vasco. Entonces, ¿por qué la integración desaparece en tantos casos? ${ }^{44}$.

El precio del transporte por carretera era muy variable, pero podía ser bastante bajo en determinados trayectos. Con todo, el ferrocarril siempre era más económico. Incluso si hubiese operado con las elevadas tarifas legales, la carreteria tendría costes superiores. Y, sin embargo, en los primeros años el ferrocarril tuvo en ésta a un competidor muy serio, que le obligó a efectuar diversas rebajas. En las Actas del Consejo de Administración de la Compañía MZA se recogen los motivos de los consejeros para aplicarlas. Una frase se repite una y otra vez: «Con la mira puesta en combatir la competencia que ejerce la carretería en el transporte de trigo, se aprueba la tarifa...». A veces, se emplean expresiones más agresivas como «matar a la carretería». Otras veces se alude al hecho de que «la mayor parte del tráfico de mercancías se efectúa por la carretera». En fin, la última de las notas de este tipo que he encontrado (supongo que habrá más) es del 18 de febrero de 1881, ¡25 años después de la ley de 1855 ! 45 .

Es interesante señalar que la competencia se ejerce tanto en los trayectos cortos (en los que las molestias e incomodidades del transbordo podían justificar el empleo de una carreta) como en los largos. Por ejemplo, el 3 de enero de 1873 MZA aprueba una tarifa que tiene por objeto «combatir la competen-

44 N. Sánchez-Albornoz (1974, pp. 131-134) ya percibió este fenómeno, que atribuyó a tres hechos: $1 .^{\circ}$ los coeficientes del período anterior eran demasiado elevados como consecuencia de las crisis agricolas; $2{ }^{\circ}$ los desórdenes de la República y la Guerra Carlista. 3. la política arancelaria librecambista. Sin embargo, estas explicaciones son insuficientes. El empleo de series diferenciadas (no ya una, sino varias veces) no resuelve la elevada integración existente con anterioridad a 1856. La Primera Guerra Carlista, mucho más grave que la Segunda, parece haber acentuado la integración. España no dejó de exportar grano en los años 70; en cambio en los años 80 o 90 las importaciones fueron enormes. De hecho, las FCC construidas con 60 meses (eludiendo los años 73/76) o las construidas con los datos de Sánchez-Albornoz, que abarcan un período más dilata do que los míos, confirman que en la década de los 70 se llegó a la mínima integración. Pero, ¿por qué las FCC caen desde la segunda mitad de la década de los 60 ? ¿Y qué decir de la construcción de la red ferroviaria? Sólo las importaciones de trigo pueden ser un elemento explica tivo; con todo, tardio.

45 En las Actas del Consejo de Administración de MZA, entre 1858 y 1883 , y sólo para el trigo y la harina o mercancias en general, he encontrado notas de este tipo en los dias $3 / 3 / 68,5 / 11$ / $68,22 / 1 / 70,4 / 2 / 70,8 / 3 / 70,20 / 1 / 71,20 / 5 / 71,22 / 6 / 71,11 / 11 / 71,14 / 5 / 72,5 / 5 / 73,27 / 6 / 73,30 /$ $5 / 79,15 / 10 / 80$ y $18 / 2 / 81$. Supongo que el número de notas referentes a otros productos aumentaria esta lista. El que no haya otras anotaciones con anterioridad a 1868 puede obedecer a que la competencia con la carretería se daba por supuesta. De todos modos, de ella se habla en los días 19/8/58 y 21/10/58. En ellos, se informa de que el coste del transporte de rubia desde Valladolid a Barcelona en carro es de ocho reales por arroba $(0,26 \mathrm{ptas} / \mathrm{ton} / \mathrm{km})$, y el de farderías desde Barcelona a Madrid de siete reales por arroba $(0,24 \mathrm{ptas} / \mathrm{ton} / \mathrm{km})$. 
cia que la carreteria hace a la línea férrea en el transporte de los trigos de Extremadura con destino a Alcoym, es decir, en una distancia de más de 400 kilómetros. Tampoco la inexistencia de líneas directas explica esta competencia. La tarifa del 20 de enero de 1871 tiene por objeto «atraer a la vía férrea el tráfico entre Guadalajara y Madrid que al presente se efectúa en su mayor parte por la carretera de Aragón»; carretera paralela a la vía. Por supuesto, también hubo muchas ocasiones en las que el ferrocarril «arrolló» a la carretería, como en Reinosa. En definitiva, hubo una «guerra» por el mercado del transporte entre carreteros y ferroviarios.

¿Cómo podían las carretas competir con el ferrocarril? La respuesta no es única. En los trayectos cortos se aprovechaba de su versatilidad y de las elevadas tarifas del ferrocarril. Por ejemplo, en 1865 en todas las líneas de la Compañia MZA se cobraba el traslado de cada tonelada de trigo o harina a 0,15 $\mathrm{ptas} / \mathrm{ton} / \mathrm{km}$ en trayectos inferiores a 145 kilómetros, a lo que habria que sumar tres o cuatro reales de carga y descarga. Si suponemos: $1 .^{\circ}$ que, como afirma Gómez Mendoza, las carretas sólo tenian que recorrer 125 kilómetros por 147 kilómetros del tren ${ }^{46} ; 2^{\circ}$ que desde la era o el molino hasta el apeadero había una distancia de 10 kilómetros; $3 .^{\circ}$ que el coste del transporte por carreta era de $0,3 \mathrm{ptas} / \mathrm{ton} / \mathrm{km}$; entonces la carretería resultaría más barata que el ferrocarril cuando el apeadero y la estación de destino se encontrasen a menos de 38 kilómetros. Si la distancia de la era o el molino al apeadero fuera de 20 kilómetros, la carreta sería más rentable en distancias inferiores a 67 kilómetros. $\mathrm{Y}$ todo ello sin tener en cuenta los costes de trasladar la mercancia desde la estación de destino al almacén, transporte que la carreta efectuaría sin más gastos.

En el transporte a larga distancia, la carreteria no puede competir con las tarifas rebajadas del ferrocarril, salvo que éste no pueda hacer todo el transporte por sí mismo, como ocurre entre Extremadura y Alcoy. Sin embargo, la combinación de la carretería y la navegación de cabotaje si puede competir. En realidad, la conexión de cualquier ciudad del pais (salvo Madrid y las de su entorno) puede efectuarse por dos rutas: directamente por el ferrocarril o a través del mar. Los consejeros de MZA percibieron esa amenaza, y la reflejaron en sus actas en muchas ocasiones y de forma similar a como lo hicieron con la carretería: «Con el fin de atraer a nuestras líneas el tráfico entre Barcelona y Granada que se efectúa al presente por los vapores...» ${ }^{47}$.

46 A. Gómez Mendoza (1989), p. 194.

47 Actas del Consejo de Administración de MZA de 20/5/71, 1/7/71, 11/11/71, 1/6/72, 19/ $6 / 72,21 / 11 / 79$ y $2 / 7 / 80$, en los mismos casos que en la nota 45 . 
Consideremos el transporte de trigo a Barcelona desde Astorga a través de Gijón, desde Écija a través de Sevilla y desde Jumilla a través de Alicante. Como precio del transporte ferroviario tomaré la tarifa especial del trigo de MZA en 1865 hasta Zaragoza, y 0,06 ptas/ton/km entre Zaragoza y Barcelona. En consecuencia, cualquier recorrido que distase más de 450 kilómetros de Zaragoza importaria 52 pesetas hasta Barcelona. El precio de la navegación por cabotaje lo he obtenido de los fletes registrados en el Boletín Oficial de Comercio de Santander de 1854, para el traslado de trigo hasta varios puertos de la peninsula, y que aún se redujo más en los años siguientes. Ese precio tiene dos componentes: un elevado coste fijo, 8,2 pesetas por tonelada, y un coste variable muy bajo, $0,005 \mathrm{ptas} / \mathrm{ton} / \mathrm{km}$. Ya me he referido a lo hipotético que resulta hablar de un precio único de la carretería; asumiendo la vaguedad del término, podemos fijar dicho precio en $0,4 \mathrm{ptas} / \mathrm{ton} / \mathrm{km}$ entre León y Gijón, y de $0,3 \mathrm{ptas} / \mathrm{ton} / \mathrm{km}$ en los otros trayectos. El cuadro 4 compara los precios finales del transporte combinado.

\section{CUADRO 4}

Coste del transporte del trigo en 1865 basta Barcelona

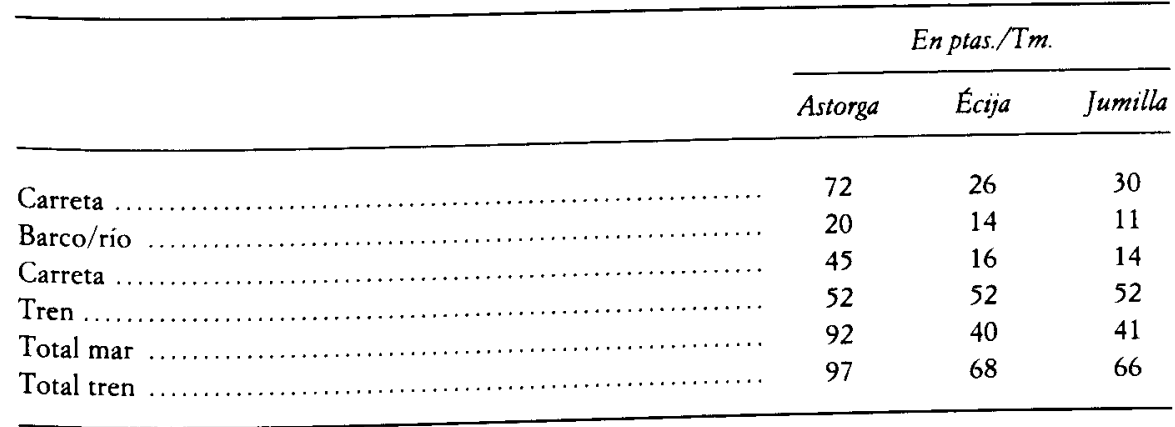

FuENTE: Véase texto.

Por supuesto, los ejemplos no han sido elegidos al azar, aunque tampoco son extraños. En los tres casos, es más barato recurrir a la navegación de cabotaje antes que al ferrocarril; por tanto, en los tres casos el volumen transportado por éste sería nulo. Asimismo, en los tres casos los ingresos que percibiría la carretería serian mayores por su combinación con el barco que con el tren, lo que le permitiria mantener mejor su oferta. 
La única solución para el ferrocarril era la aplicación de tarifas rebajadas; pero ello no era fácil. El ferrocarril español operaba con costes muy elevados, y tenía parcos ingresos. La conexión de Zaragoza con Madrid y Barcelona trajo una guerra de tarifas entre Norte y MZA, que desembocó en la crisis de 1866. Es más, la tarifa de 1865 , que ha sido la empleada para elaborar el cuadro anterior, es la que marca el punto culminante de dicha guerra. Según los datos de Tortella, tanto los ingresos brutos totales como por kilómetro de las compañias ferroviarias cayeron de forma notable en aquel año ${ }^{48}$. Asi pues, las compañias ferroviarias se vieron empujadas a la colaboración. Por un lado se ofrecieron tarifas aún más bajas a larga distancia. Por otro, aumentaron los recorridos medios de cada mercancia. Pere Pascual ${ }^{49}$ ha descrito el desvío del transporte de harinas desde la vía marítima que enlazaba Santander con Barcelona a la vía terrestre de Zaragoza. Pero éste no será ni el primero ni el único caso. La colaboración entre MZA, Norte y ZPB (posteriormente absorbida por Norte) permitió absorber el mercado de trigos portugueses, extremeños y cordobeses, anteriormente comercializados por Santander y Sevilla.

Respecto a los trayectos a corta distancia, MZA aprobó varias tarifas que tenían como finalidad destruirlos. Esta intención resulta bastante evidente en la tarifa antes citada del 20 de enero de 1871 , destinada a combatir la competencia de la carretería entre Guadalajara y Madrid. Un año más tarde, el 14 de mayo de 1872, en las Actas del Consejo de Administración de MZA se decide que:

Habiendo cesado las causas que aconsejaron la creación de la tarifa especial n. ${ }^{\circ} 28$ para el transporte de mercancias a pequeña velocidad entre las Estaciones comprendidas en el trayecto de Madrid a Guadalajara, se acuerda la anulación de dicha tarifa, a contar desde el $1 .{ }^{\circ}$ de junio próximo.

Alcanzados los objetivos perseguidos, ¿para qué mantener la rebaja? La misma finalidad debieron tener muchas tarifas aprobadas en los primeros años 70 dirigidas a productos y/o trayectos muy concretos. Ello anulaba la posibilidad de la carretería de rebajar sus costes por medio de los viajes de retorno.

De esta forma, en los primeros años 70 la carretería empezó a morir. Por diversas razones, es difícil hacerse una idea de ello a través de los censos ganaderos. Una forma indirecta consiste en analizar la evolución del trigo y la harina comercializados por Norte y MZA, que aparece en el gráfico $9{ }^{50}$. En realidad,

${ }^{48}$ G. Tortella Casares (1985), pp. 183-187.

49 P. Pascual Domenech (1990).

so R. Anes Alvarez (1978), pp. 497 y 501. Para los años 1867 y 1868 de MZA he recurrido a las Actas de la Junta de Accionistas. 


\section{GRÁFICO 9}

Cereales y barinas transportados por las compañias Norte y $M Z A$

(Datos en millones de Tm)

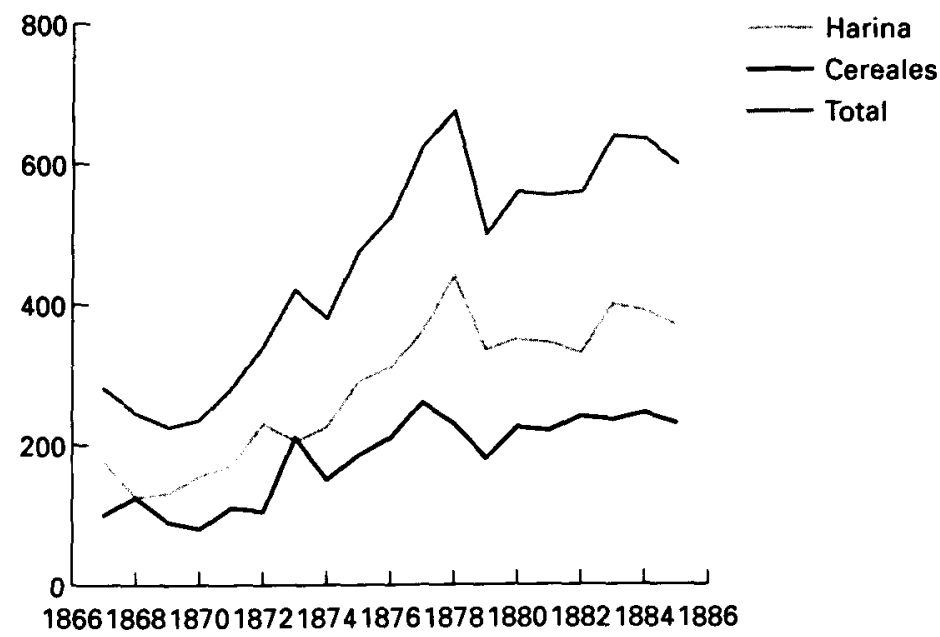

Fuente: Rafael Anes (1978, pp. 496-501) y Actas de la Junta de Accionistas de MZA (1867 y 1868).

hubo que esperar hasta el fin de la crisis de 1868, y de las importaciones de 1869 , para que las compañias ferroviarias pudieran captar un volumen superior del mercado del transporte. Pero a finales de los 70 Norte y MZA transportaban dos y hasta tres veces más trigo y harina que en los 60 .

Dueñas absolutas del transporte del trigo, las compañias ferroviarias empezaron a canalizarlo hacia destinos muy concretos, que aunque para ellas pudieran tener una justificación económica, no la tenían para el sector agrario y la economia en general. Así, Antonio Peiró observa que las tarifas especiales concedidas a la introducción de granos castellanos en Cataluña dificultaron el desarrollo de la industria harinera aragonesa ${ }^{51}$. Otra ineficiencia fue la ejecución de recorridos innecesariamente largos. Siguiendo a Pascual y a Peiró, si comparamos los kilómetros recorridos por los trigos y harinas vallisoletanos hacia Barcelona y los zaragozanos hacia Madrid, con los que hubieran recorrido en el supuesto de que Valladolid hubiera provisto a Madrid y Zaragoza a Barcelona, el resultado es que el conjunto de éstos hacian recorridos dobles a los que debieron haber hecho con la carretería.

"A. Peiró (1987), pp. 228-229. 
Si la competencia desaparecia del interior peninsular, en la costa se reavivaba. La progresiva llegada del trigo y las harinas extranjeros, procedentes tanto del Este (Ucrania) como del Oeste (Estados Unidos) hizo que los trigos y harinas nacionales tuviesen mayores dificultades para venderse. Se configura así un mercado dual, con un sistema monopolístico interior, y una periferia abierta a la competencia. Semejante estructura no contribuyó en nada a la integración del mercado nacional. Si la conexión entre las provincias interiores se desvanecía por efecto de la propia política ferroviaria, la conexión entre estas provincias y las costeras también se debilitaba como consecuencia de la falta de competitividad ante el trigo foráneo. Sin embargo, algunas provincias no sólo no perdieron integración, sino que la ganaron. Favorecidos por tarifas extremadamente bajas, los granos recorrían enormes distancias para alimentar a la población de las grandes ciudades. De esta forma, el ferrocarril no sólo fue un elemento de destrucción del mercado nacional del trigo. Su papel es más complejo, atando y desatando. A la postre, polarizó el mercado en torno a ciertas líneas.

\section{CONCLUSIÓN}

En España el ferrocarril se construyó como consecuencia de una decisión política. Si hubiera dependido de la iniciativa privada, las líneas abiertas al tráfico hubieran sido muy pocas, y en regiones como Extremadura, Galicia o Andalucía nunca se hubieran oído las sirenas de las máquinas a vapor. En 1855 el Gobierno decidió asumir el riesgo porque creyó que el premio compensaba los esfuerzos. Al fin y al cabo, y como tantas veces se ha repetido, «que el pais haga caminos de hierro, que los caminos de hierro harán al pais» 52.

Pero, ¿era tan urgente construirlo? En lo que hace al mercado del trigo, la respuesta parece negativa. Los costes de transporte de la carreteria, combinados con los de la navegación de cabotaje, eran bajos alli donde el tráfico era frecuente; es de imaginar que aún hubieran bajado más. No tiene nada de extraño que los mercados estuviesen muy bien conectados a mediados de siglo. La gran similitud de las diferencias de precios y de los costes de transporte sugiere que los costes de intermediación eran bajos, como sucede en un sector atomizado ${ }^{53}$. Desde cualquier punto de vista, el mercado de trigo a mediados de siglo era «eficiente».

52 J. Nadal i Oller (1992), p. 47.

53 Una opinión diferente puede encontrarse en J. Moreno Lázaro (1995, pp. 244-246) y A. Hoyo Aparicio (1993, p. 89), aunque ambos se refieren al tráfico de harinas, y sólo a la ruta de- 
Si el ferrocarril se hubiese limitado a proporcionar un transporte más barato, esa integración hubiese seguido siendo alta, al menos hasta finales de los 70. Pero hizo algo más. Rompió los vínculos comerciales de muchas regiones para favorecer trayectos muy concretos, con destino en Madrid y Barcelona. No parece que una política de este tipo haya sido la más adecuada para un desarrollo equilibrado del país. Es muy conocida la posición crítica de Gabriel Tortella sobre el ferrocarril. Este trabajo la confirma de dos maneras: $1 .^{\circ} \mathrm{El}$ ferrocarril era innecesario, al existir una alternativa en la carretería. $2^{\circ}$ El ferrocarril redujo la integración entre muchos mercados, con lo que no sólo no generó efectos hacia adelante en la industria harinera, sino que eliminó muchos de los que ya existian. El hecho de que el transporte del trigo no sea independiente del de otros productos sugiere que estas conclusiones podrían generalizarse a sus mercados. Pero, en tanto en cuanto no se realicen nuevas investigaciones, en ellos sólo pueden ser formuladas a título de hipótesis.

\section{FUENTES DOCUMENTALES}

Actas del Consejo de Administración de la Compañia de Madrid-Alicante-Zaragoza. Fundación de los Ferrocarriles.

Actas de la Junta de Accionistas de la Compañia Madrid-Alicante-Zaragoza. Fundación de los Ferrocarriles.

Archivos municipales:

Burgos. Sección estadistica: legajos 155, 156, 250-258, 267, 286-304, 310, 313, 367 $374,426-428,431$ y 453.

Córdoba. Cajas 1044 a 1050 y 2434.

Granada. Libros 1976-2034.

Huesca. Caja 69.1.

La Coruña. Sección abastos. Fe de valores.

León. Caja 365.

Lorca. Legajo 66. Sección 2.

Lérida. Legajos 306 y 307.

Reinosa. Pero tampoco en dicho mercado sus argumentos son convincentes. El primero deduce el encarecimiento de la harina en los años 30 de la existencia de prácticas monopolísticas. Pero sólo ofrece confirmación en el aprovisionamiento del Ejército, y no parece que pudieran desarrollarse en los años 40 en otros mercados. A mi entender, los datos que presenta sobre las relaciones comerciales de la industria harinera antes probarian la atomización del sector harinero que su cartelización. Andrés Hoyo Aparicio sí que mide esos costes de intermediación, pero incluye en ellos los beneficios extraordinarios generados por el distanciamiento de los precios de las plazas de la costa y del interior, señalado en la página 35 . He efectuado una estimación similar a la suya (tráfico de harina entre Valladolid y Santander), y en ella los costes de intermediación se reducen al $8 \%$ del coste del producto antes del ferrocarril, y al $2 \%$ después. 
Medina de Rioseco. Caja 266.

Mérida. Legajo 811.

Oviedo. Libro de valias.

Pamplona. Sección almudi: legs. 8, 11, 12, 17, 33 y 34.

Santander. Cajas 59, 60 y 61 .

Santiago. Legajo 26-2-1.

Segovia. Legajos 1216-1, 1272-32, 1336-1, X-63-2 y 3, XX-479-3, XXI-522-1 al 4, XX1-542-1, XXXII-958, XXXIII-984-5, XXXIV-1020, XXXIV-1021-2, XXXVII-1085-6 y 10 y XXXVII-1094-1.

Toledo. Libros de precios.

Tolosa. Legajos A 9 III 1 y 2 , A 9 IV 1 y 2 y A 9 V.

Vitoria. Legajos 35/09/31, 35/09/74, 35/12/39, 35/14/29, 35/15/66, 37/28/12, 37/ $29 / 05$ y $04 / 15 / 08$.

Zaragoza. Cajas 75 a 79.

Boletines Oficiales de las provincias antedichas. Pueden consultarse en los archivos de sus Diputaciones o en la Biblioteca Nacional.

Boletín Oficial de Comercio de Santander. Cámara Oficial de Comercio e Industria y Bi-

blioteca Municipal de Santander.

Diario de Barcelona. Biblioteca de Catalunya. Sign. 07(46.71 BAR).

Despertador Montañés, El. Biblioteca Municipal de Santander.

Diario Constitucional de Zaragoza. Archivo Municipal. Sig 161-174.

Información Agraria de Castilla y León. Junta de Castilla y León.

\section{BIBLIOGRAFIA}

ANes Álvarez, G. (1970): Las crisis agrarias en la España moderna, Madrid, Taurus. (1988): Economía y Sociedad en la Asturias del Antiguo Régimen, Barcelona, Ariel.

ANes Álvarez, R. (1978): «Relaciones entre el ferrocarril y la economía española (18651935)», en Los ferrocarriles en España, 1844-1943, vol. II, Madrid, Banco de España, pp. 357-529.

ARTOLA, M. (1978): Introducción de Los ferrocarriles en España, 1844-1943, vol. I, Madrid, Banco de España, pp. 13-25.

BARNETT, V. (1995): «Soviet commodity markets during NEP», en The Economic History Review, vol. XLVIII, n. ${ }^{\circ}$ 2, mayo, pp. 329-352.

Barquin GiL, R. (1995): «Precios del trigo en el Norte de España (1814-1883)», en VII Congreso de Historia Agraria, Baeza.

Chevet, J. M., y Saint-Amour, P. (1991): «L'integration des marchés du blé en France au XIX' sièclem, en Histoire \& Mesure, VI-1/2, pp. 93-119.

Deane, P. (1988): La Primera Revolución Industrial, Madrid, Peninsula.

Fradera Barceló, J. M. ${ }^{a}$ (1984): «El comercio de cereales y la prohibición de 1820 (el caso del mercado catalán)», en Agricultura y Sociedad, n. ${ }^{0} 30$, pp. 137-168.

(1987): Industria i mercat, Barcelona, Crítica.

Garcta SANZ, A. (1985): "Crisis de la agricultura tradicional y revolución liberal», en Historia Agraria de la España contemporánea, vol. I, pp. 7-99, Barcelona, Critica. 
Garrabou, R.; Pujol, J., y Colome, J. (1991): «Salaris, us i explotació de la força de treball agricola (Catalunya 1818-1936)», en Recerques, n. 24 , pp. 23-52.

GARRABOU, R., y SANZ, J. (1985): «La agricultura española durante el siglo XIX. ¿Inmovilismo o cambio?», en Historia Agraria de la España contemporánea, vol. I, pp. 7-191, Barcelona, Critica.

Gomez MendozA, A. (1982): Ferrocarriles y cambio económico en España, 1855-1913. Un enfoque de Nueva Historia Económica, Madrid, Alianza.

- (1989): Ferrocarril, industria y mercado en la modernización de España, Madrid, Espasa Calpe.

Helguera Qujada, J. (1988): «Aproximación a la historia del Canal de Castilla», en El Canal de Castilla, pp. 11-159, Valladolid, Junta de Castilla y León.

Hoyo Aparicio, A. (1993): Todo mudó de repente, Santander, Universidad de Cantabria.

KonDO, A. Y. (1990): La agricultura española del siglo XIX, Madrid, Nerea.

LLOPIS AgELÁN, E. (1985): «Algunas consideraciones acerca de la producción agraria castellana en los últimos años del Antiguo Régimen», en Historia Agraria de la España contemporánea, vol. I, pp. 129-150, Barcelona, Crítica.

Madrazo Madrazo, S. (1984): El sistema de transportes en España, 1750-1850, Madrid, Turner.

Moreno LÁzaro, J. (1995): «Protección arancelaria, distorsiones de mercado y beneficios extraordinarios: la producción de harinas en Castilla la Vieja, 1820-1841», en Revista de Historia Económica, año XIII, n. ${ }^{\circ}$ 2, pp. 227-250.

NADAL y Oller, J. (1992): El fracaso de la Revolución Industrial en España. 1814-1913, Barcelona, Ariel.

Pascual Domenech, P. (1990): Agricultura i industrializació a la Catalunya del segle XIX, Barcelona, Crítica.

PeIRO, A. (1987): «El mercado de cereales y aceites aragoneses (siglos XVil-XX)», en Agricultura y Sociedad, n. ${ }^{\circ} 43$, pp. 213-279.

Pena Sánchez de Rivera, D., y Sánchez-Albornoz, N. (1983): Dependencia dinámica entre precios agricolas. El trigo en España, 1857-1890. Un estudio empírico, Madrid, Banco de España.

Perez Moreda, V. (1985): «La modernización demográfica, 1800-1930. Sus limitaciones y cronologia», en La modernización económica de España 1830-1930, pp. 25-62, Madrid, Alianza.

Pérez Picazo, M. T. (1990): «Salarios y niveles de vida en la agricultura murciana durante el siglo XIX», XV Simposi d'Anàlisi Econòmica. Secció Història Econòmica. Nivells de vida a Espanya s. XIX y XX, vol. I, pp. 250-260, Barcelona.

Reher, D. S., y Ballesteros, E. (1993): «Precios y salarios en Castilla la Nueva: la construcción de un indice de salarios reales 1501-1991», en Revista de Historia Económica, año XI, n. ${ }^{\circ} 1$, pp. 101-151.

Ringrose, D. R. (1972): Los transportes y el estancamiento económico de España (1750-1850), Madrid, Tecnos.

ROEHNER, B. (1994): «Les mécanismes d'interdépendance spatiale entre marchés du blé au XIXe siècle», en Histoire économie et société, n. ${ }^{\circ} 2$.

Rubio Pérez, L. (1986): Producción agraria en la zona norte castellano-leonesa durante la edad moderna, León, Universidad de León.

Rueda Hernanz, G. (1986): La desamortización de Mendizábal y Espartero en España, Madrid, Cátedra. 
SÁNCHEZ-ALBORNOZ, N. (1975): Los precios agrícolas durante la segunda mitad del siglo XIX, Madrid, Banco de España.

- (1974): Jalones en la modernización de España, Madrid, Ariel.

SARDA DEXEUS, J. (1970): La política monetaria y las fluctuaciones de la economía española en el siglo XIX, Barcelona, Ariel.

SERENI, E. (1980): Capitalismo y mercado nacional, Barcelona, Crítica.

SLicher VAN BATH, B. H. (1978): Historia agraria de Europa occidental 500-1850, Madrid, Península.

TORTElla CASARES, G. (1985): «Producción y productividad agraria», en La modernización económica de España 1830-1930, pp. 63-88, Madrid, Alianza. (1995): Los origenes del capitalismo en España, Madrid, Tecnos.

VIDal Olivares, J. (1991): Transportes y mercado en el País Valenciano (1850-1914), Valencia, Edicions Alfons el Magnànim.

Yun Casalilla, B. (1987): Sobre la transición del capitalismo en Castilla. Economia y Sociedad en Tierra de Campos (1500-1830), Salamanca, Junta de Castilla y León. 